\title{
Immunoelectroosmophoresis in the diagnosis of meningococcal infections
}

\author{
BARBARA M. TOBIN AND D. M. JONES \\ From the Public Health Laboratory, Withington Hospital, Manchester
}

SYNOPSIS Specimens of cerebrospinal fluid and serum from 22 cases of meningococcal infection were examined by immunoelectroosmophoresis and the results compared with those obtained by microscopy and culture. The results were the same except that three of 10 cases of group B infection were not diagnosed by immunoelectroosmophoresis and two of 10 cases of group $\mathrm{C}$ infection were not diagnosed by culture. The sensitivity of the method depends on the potency of the antiserum used and antisera from commercial sources were satisfactory except for those prepared against group B meningococci. The method may be more sensitive than microscopy and culture under certain conditions, in particular, where the patient has already begun antibiotic treatment, where the specimens have become contaminated and, where the infecting organism is either a group A or group $\mathrm{C}$ meningococcus.

The laboratory diagnosis of meningococcal infection usually involves conventional microscopy and culture techniques that require a certain amount of time and which, because of previous antibiotic therapy, may sometimes fail. For many years it has been known that meningococcal antigens may be detected in cerebrospinal fluid (CSF) by precipitin techniques (Rake, 1933; Maegraith, 1935). However, these methods were not sufficiently sensitive to replace microscopy and culture and were not adopted as standard laboratory procedures. The counter current immunoelectrophoretic technique (Culliford, 1964), developed for the detection of small amounts of antigen, has been widely used for the detection of Australia antigen (Prince and Burke, 1970) and is more rapid and more sensitive than other double diffusion methods (White, Lasheen, Baillie, and Turner, 1971). This technique has been applied to the detection of meningococcal antigen in CSF and serum of patients with meningococcal infections both in the United States (Edwards, 1971) and in Africa (Greenwood, Whittle, and Dominic-Rajkovic, 1971). We report our experience with this technique for the diagnosis of the types of meningococcal infection currently encountered in the United Kingdom.

\section{Methods}

Specimens of CSF and serum from patients with Received for publication 20 April 1972. meningitis and septicaemia were received from a number of hospital and public health laboratories in England. The majority of the specimens were from cases where the diagnosis had already been established but in some cases the diagnosis was not known.

\section{Antisera}

The antisera that we used routinely for testing clinical specimens were prepared in the Manchester Public Health Laboratory (Abbott and Graves, 1972). We compared these antisera with commercially available sera (Burroughs Wellcome and Difco) and we were also able to use sera kindly supplied by Dr N. A. Vedros of the Neisseria Repository, California.

\section{Antigens}

For the development of the immunoelectroosmophoresis method and for comparing the activity of different sera we prepared simple saline extracts of meningococci. The strains (group A M1027, group B BM993, group C M1628, Sara Branham) were grown on Difco Mueller Hinton agar with Difco supplement B overnight (groups A and C) or for six hours only (group B) before harvesting into saline with a cotton wool swab. After 24 hours at $4^{\circ} \mathrm{C}$, merthiolate was added, the suspension was centrifuged to remove most of the organisms and then stored at $4^{\circ} \mathrm{C}$. 


\section{Immunoelectroosmophoresis}

The method is adapted from White et al (1971). Hyland immunoplates were coated with a gel consisting of $0.9 \%$ agarose in buffer containing $0 \cdot 1 \mathrm{M}$ sodium chloride, $0.01 \mathrm{M}$ tri (hydroxymethyl) methylamine (tris) and $0.001 \mathrm{M}$ ethylene diamine tetracetic acid (EDTA). Three pairs of holes $2 \mathrm{~mm}$ in diameter and $6 \mathrm{~mm}$ apart were punched in the gel for each test and up to 12 pairs in each slide. Serum or cerebrospinal fluid was placed in the three holes on the cathodal side and antiserum to groups A, B, and $\mathrm{C}$ in the corresponding anodal wells. The slide was connected to barbitone buffer $p H \quad 8.4$ in an electrophoresis tank by Whatman $3 \mathrm{MM}$ paper wicks and subjected to a constant current of $4 \mathrm{~mA}$ per slide for up to three hours. Strong reactions were visible in 30 to 40 minutes and these precipitin lines may become blurred with continued passage of current; weak reactions were not seen for two and a half to three hours.

\section{Results}

The maximum dilutions of saline antigens that could be detected by immunoelectroosmophoresis are shown in Table I. It should be noted that the

\begin{tabular}{|c|c|c|c|c|c|}
\hline \multirow{2}{*}{\multicolumn{2}{|c|}{ Antiserum }} & \multirow{2}{*}{$\begin{array}{l}\text { Reciprocal } \\
\text { of } \\
\text { Haemag- } \\
\text { glutination } \\
\text { Titre }\end{array}$} & \multicolumn{3}{|c|}{$\begin{array}{l}\text { Reciprocal of Maximum Dilution } \\
\text { of Antigen Detected }\end{array}$} \\
\hline & & & $\begin{array}{l}\text { Neat } \\
\text { Serum }\end{array}$ & Serum 1:2 & Serum 1:4 \\
\hline \multirow{3}{*}{ Group A } & B.W. & 200 & 1000 & 500 & - \\
\hline & Difco & 800 & 4000 & 8000 & 8000 \\
\hline & Manchester & 3200 & 8000 & 8000 & 8000 \\
\hline \multirow{3}{*}{ Group B } & B.W. & 1600 & Neat & $\longrightarrow$ & $\longrightarrow$ \\
\hline & Difco & 1600 & Neat & - & - \\
\hline & Manchester & 3200 & 16 & 8 & 4 \\
\hline \multirow[t]{3}{*}{ Group C } & B.W. & 800 & 2000 & 2000 & \\
\hline & Difco & 1600 & 2000 & 2000 & 2000 \\
\hline & Manchester & 6400 & 2000 & 2000 & 2000 \\
\hline
\end{tabular}

Table I Comparison of antisera by haemagglutination and immunoelectroosmophoresis

antigens used in these tests were made from the identical strains of meningococci which were used to prepare the Manchester antisera. All the antisera have satisfactory titres of activity as measured by haemagglutination but appear to vary in their content of precipitating antibody. The sensitivity of the antigen-detecting system is high with group A and group $\mathrm{C}$ but the group $\mathrm{B}$ system appears to be less sensitive, particularly using commercial sera. The antisera prepared by Vedros had the same activity as those prepared in Manchester.

Of 27 cases of meningitis or septicaemia, 22 were diagnosed as meningococcal infections (Table II) the remainder were one case of Haemophilus 을 meningitis, one case where a few Gram-negative $\overrightarrow{\vec{D}}$ diplococci were seen but no bacteria were grown, and three cases where the results of microscopy, culture, and immunoelectroosmophoresis (including pneumococcal antigens) were all negative. Where specimens of fluid taken on the day following $\stackrel{\mathbb{D}}{\circ}$ the first intrathecal dose of penicillin were available, $\stackrel{\infty}{\infty}$ these were found to be negative on immunoelectro- $\overrightarrow{0}$ osmophoresis. Positive results by immunoelectroosmophoresis were obtained from a grossly $\vec{\omega}$ contaminated fluid collected at necropsy where the diagnosis would not have been made otherwise and $?$ also from extracts of a variety of tissues in a fatal $\mathrm{N}$ case of septicaemia where a serum dilution of 1/128 $-\mathrm{V}$ gave a clear precipitin line.

\begin{tabular}{|c|c|c|c|c|c|}
\hline \multirow[t]{2}{*}{ Infection } & \multirow[t]{2}{*}{ No. } & \multicolumn{2}{|c|}{ Culture } & \multicolumn{2}{|c|}{ Immunoelectrophoresis } \\
\hline & & $C S F$ & Blood & $C S F$ & Serum \\
\hline
\end{tabular}

\begin{tabular}{lllll}
\hline Group A & 1 & $\ldots$ & - & \\
Group B & 1 & - & - & \\
Group C & 3 & - & & \\
& 5 & - & - & \\
& 2 & - & - & \\
\hline
\end{tabular}

Table II Results of culture and immunoelectroosmophoresis of cerebrospinal fluid and serum from meningococcal infections

In three group B infections where the immunoelectroosmophoresis was negative, the growth was? reported as two colonies, scanty and moderate respectively. Group B antigen was only detected in one specimen of fluid after treatment with Lyphogel (Gelman). Two cases of group C infection that were positive only by immunoelectroosmophoresis had both received antibiotic therapy before admission. $\frac{D}{2}$ The diagnosis was further confirmed in both these cases by the detection of a rise in titre of haemag- No glutinating antibody to group $\mathrm{C}$ antigen in convalescence.

\section{Discussion}

This study confirms that immunoelectroosmophoresis is a reliable method of diagnosing meningo- ? coccal infections. The sensitivity of the method depends on the potency and specificity of the antisera used. There is no difficulty in the preparation of antisera to group $\mathrm{A}$ and group $\mathrm{C}$ meningococci and for these infections immunoelectrophoresis is $\overline{0}$ at least as sensitive as conventional microscopy and 
culture. Good antiserum to group B organisms is not so easy to prepare, and, because of this, the sensitivity of the technique may be reduced. The group B antisera from commercial sources failed to detect any antigen in clinical specimens. It is of interest to note that where the method has been applied successfully using commercially available sera the prevalent strains have been group $A$ in Africa and group $C$ in the USA. Where we failed to get correlation between positive culture and immunoelectroosmophoresis, the cases were all group B infections, although probably with very small numbers of organisms present in the cerebrospinal fluid.

Two cases of meningitis treated with antibiotics before admission were positive by immunoelectroosmophoresis and negative by culture, although organisms were seen in the cerebrospinal fluid of one of these. These results and those obtained from cerebrospinal fluid on the second day of treatment suggest that antigen may remain detectable for up to 24 hours after effective treatment has begun although in a partially treated case we have detected antigen in the cerebrospinal fluid on the third day of treatment. We have shown that specimens may be stored satisfactorily at room temperature or lower temperatures and that contamination by other bacteria does not affect the test.

We were not able to test many samples of serum taken early in the disease but by examining both serum and cerebrospinal fluid the diagnosis is more likely to be established. Antigen was more likely to be detected in the serum of those cases where there was a rash, and, in contrast to the findings of Edwards (1971), the presence of antigen in the blood stream did not indicate a poor prognosis.

We wish to thank the many colleagues who kindly sent specimens for examination. This investigation was supported by a grant from the Manchester Regional Hospital Board.

\section{References}

Abbott, J. D., and Graves, J. F. R. (1972). Serotype and sulphonamide sensitivity of meningococci isolated from 1966 to 1971. J. clin. Path., 25, 528-530.

Culliford, B. J. (1964). Precipitin reactions in forensic problems. Nature (Lond.), 201, 1092-1094.

Edwards, E. A. (1971). Immunologic investigations of meningococcas disease. I. Group specific Neisseria meningitidis antigenpresent in the seruin of patients with fulminant meningococcaemia. J. Immunol., 106, 314-317.

Greenwood, B. M., Whittle, H. C., and Dominic-Rajkovic, O. (1971). Counter-current immunoelectrophoresis in the diagnosis of meningococcal infections. Lancet, 2, 519-521.

Maegraith, B. G. (1935). The rapid diagnosis of cerebrospinal fever. Lancet, $1,545-546$.

Prince, A. M., and Burke, K. (1970). Serum hepatitis antigen (SH): rapid detection by high voltage immunoelectroosmophoresis. Science, 169, 593-595.

Rake, G. (1933). Studies on meningococcus infection. V. The presence of meningococcus precipitinogens in the cerebrospinal fluid. J. exp. Med., 58, 375-383.

White, G. B. B., Lasheen, R. M., Baillie, M. B., and Turner, G. C. (1971). Comparison of three serological methods for the detection of hepatitis-associated antigen. J. clin. Path., 24, 8-12. 